\title{
Laboratory investigation of photochemical oxidation of organic aerosol from wood fires 1: measurement and simulation of organic aerosol evolution
}

\author{
A. P. Grieshop, J. M. Logue, N. M. Donahue, and A. L. Robinson \\ Center for Atmospheric Particle Studies, Carnegie Mellon University, Pittsburgh, Pennsylvania, USA \\ Received: 3 July 2008 - Published in Atmos. Chem. Phys. Discuss.: 18 August 2008 \\ Revised: 9 January 2009 - Accepted: 9 January 2009 - Published: 18 February 2009
}

\begin{abstract}
Experiments were conducted to investigate the effects of photo-oxidation on organic aerosol (OA) emissions from flaming and smoldering hard- and soft-wood fires under plume-like conditions. This was done by exposing the dilute emissions from a small wood stove to UV light in a smog chamber and measuring the gas- and particle-phase pollutant concentrations with a suite of instruments including a Proton Transfer Reaction Mass Spectrometer (PTRMS), an Aerosol Mass Spectrometer (AMS) and a thermodenuder. The measurements highlight how atmospheric processing can lead to considerable evolution of the mass and volatility of biomass-burning OA. Photochemical oxidation produced substantial new $\mathrm{OA}$, increasing concentrations by a factor of 1.5 to 2.8 after several hours of exposure to typical summertime hydroxyl radical $(\mathrm{OH})$ concentrations. Less than $20 \%$ of this new OA could be explained using a stateof-the-art secondary organic aerosol model and the measured decay of traditional SOA precursors. The thermodenuder data indicate that the primary $\mathrm{OA}$ is semivolatile; at $50^{\circ} \mathrm{C}$ between 50 and $80 \%$ of the fresh primary OA evaporated. Aging reduced the volatility of the $\mathrm{OA}$; at $50^{\circ} \mathrm{C}$ only 20 to $40 \%$ of aged OA evaporated. The predictions of a volatility basis-set model that explicitly tracks the partitioning and aging of low-volatility organics was compared to the chamber data. The OA production can be explained by the oxidation of low-volatility organic vapors; the model can also reproduce observed changes in OA volatility and composition. The model was used to investigate the competition between photochemical processing and dilution on OA concentrations in plumes.
\end{abstract}

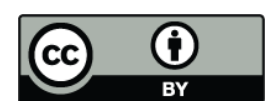

Correspondence to: A. L. Robinson (alr@andrew.cmu.edu)

\section{Introduction}

Combustion of biomass is a major source of gas- and particle-phase air pollution on urban (Robinson et al., 2006; Schauer and Cass, 2000), regional (Wotawa and Trainer, 2000) and global (Lelieveld et al., 2001) scales. Biomassburning is estimated to contribute approximately one-third of total fine particle mass in the US (Watson, 2002) and $90 \%$ of the global emissions of primary particulate organic carbon (OC) from combustion sources (Bond et al., 2004). Light-absorbing carbonaceous aerosols emitted by largescale biomass fires in South America, Asia and Africa are thought to have continental- and global-scale climate impacts (Andreae et al., 2004; Ramanathan et al., 2007).

Biomass burning encompasses a range of sources including space heating, cooking, wildfires and prescribed burns. The emissions from all of these sources are highly variable, with fuel type, moisture content and combustion conditions all having large influences on the chemical and physical properties of the gas- and condensed-phase emissions (Reid et al., 2005).

Biomass burning emits a complex mixture of organics that span a wide range of volatility. Some of these organics have very low vapor pressures and thus partition directly into the particle phase, creating primary organic aerosol (POA). Biomass burning also emits volatile organic compounds (VOCs); some of these, such as light aromatics, are known precursors for secondary organic aerosol (SOA). SOA is formed when photo-oxidation of gas-phase organics produces low-volatility products that partition into the condensed phase. Source dilution experiments have shown that a large fraction of wood-smoke POA is semivolatile (Lipsky and Robinson, 2006; Shrivastava et al., 2006). Therefore, low-volatility organic vapors also exist in plumes.

Published by Copernicus Publications on behalf of the European Geosciences Union. 
A number of field studies report substantial production of organic aerosol (OA) in biomass-burning plumes that cannot be explained with current models (Reid et al., 2005). Lee et al. (2008) inferred a 1.5- to 6-fold enhancement of OA in a prescribed burn plume within 3 to $4 \mathrm{~h}$ after emission. Sizeable production has also been reported for savannah fire plumes in South Africa (Abel et al., 2003; Hobbs et al., 2003). Concentrations of organic acids can also be enriched in biomass-burning plumes (Nopmongcol et al., 2007; Peltier et al., 2007; Reid et al., 1998). Nopmongcol et al. (2007) proposed that the excess OA levels were due to acid-catalyzed heterogeneous SOA formation; Lee et al. (2008) hypothesized that they might be due to enhanced isoprenoid emissions.

Recent laboratory experiments have shown that photochemical aging of diluted diesel exhaust produces large amounts of OA, much more than can be explained with traditional SOA precursors (Robinson, 2007; Sage et al., 2008; Weitkamp et al., 2007). That work demonstrated the important linkages between the gas-particle partitioning of SVOCs and aging; elucidating this relationship for other emission sources is an important need.

This paper describes laboratory aging experiments carried out to investigate OA production from photo-oxidation of emissions from hard- and soft-wood fires in a wood stove under plume-like conditions. The experiments are designed to bridge the gap between field observations and laboratory studies of source emissions and SOA formation from single precursors. The specific objectives include: 1) quantifying the production of OA due to photo-oxidation of biomass smoke plumes; 2) assessing whether or not this production can be described by the measured decay of known SOA precursors; 3 ) measuring the effects of aging on OA volatility; and 4) comparing the measured behavior to predictions of the model proposed by Robinson et al. (2007) that explicitly accounts for partitioning and aging of primary emissions. The paper closes with a comparison of the results from these experiments to previously published field data from biomassburning plumes.

\section{Methods}

The effects of photochemical aging on wood smoke were investigated by injecting emissions into the Carnegie Mellon University (CMU) smog chamber and then aging the diluted emissions via photochemistry initiated by UV lights. The smog chamber is a temperature-controlled room containing a $12 \mathrm{~m}^{3}$ Teflon-bag (Presto et al., 2005a). Before each experiment, the chamber was cleaned by irradiation, heat $\left(40^{\circ} \mathrm{C}\right)$, and continuous flushing with dry, HEPA-filtered and activated-carbon-filtered air overnight. After cleaning, the lights were turned off, and the chamber temperature was reduced to $22^{\circ} \mathrm{C}$ with an initial relative humidity of $\sim 5 \%$.
A small amount of exhaust was added to the chamber through a heated inlet connected to a small wood stove $(\mathrm{Ca}-$ bela's Sheepherder Packer Stove). The fuels included (in separate experiments) mixed hardwoods, Laurel Oak and Yellow Pine. The emissions were injected during a variety of combustion conditions, from smoldering to active flaming. The fuel wood was cut into small (approximately $4 \times 4 \times 20 \mathrm{~cm}$ ) pieces and the fire was allowed to burn for $\sim 30$ min to allow the stove and chimney to reach a normal operating temperature. Exhaust was injected into the chamber using an ejector dilutor (Dekati DI 1000) connected to the stack of the stove about $30 \mathrm{~cm}$ above the fire box. The ejector diluter was operated with HEPA and activated-carbonfiltered air heated to $350^{\circ} \mathrm{C}$. All sampling and transfer lines were also maintained at $350^{\circ} \mathrm{C}$. Upon entering the chamber, the exhaust was rapidly diluted and cooled. Initial particulate matter concentrations were tens to hundreds of $\mu \mathrm{g} \mathrm{m}^{-3}$ of predominantly carbonaceous material. Conditions were thus "near ambient", consistent with plumes downwind of a point source. In two experiments, $\mathrm{NO}_{\mathrm{x}}$ levels in the wood smoke were very low, so additional $\mathrm{NO}$ was injected into the chamber before turning on the UV lights.

After allowing time for mixing and initial data collection, the UV lights in the smog chamber were turned on to initiate photo-oxidation reactions (General Electric Model 10526 blacklights). These lights yield an $\mathrm{NO}_{2}$ photolysis rate $\left(\mathrm{J}_{\mathrm{NO}_{2}}\right.$ ) of approximately $0.2 \mathrm{~min}^{-1}$ (roughly equivalent to solar radiation at a $70^{\circ}$ zenith angle (Carter et al., 2005). The experiments were conducted at $22 \pm 2^{\circ} \mathrm{C}$. The basic experimental procedures were similar to the diesel aging experiments described by Weitkamp et al. (2007), with the addition of continuous aerosol black carbon (BC) and volatility measurements and a more extensive set of VOC measurements.

\subsection{Instrumentation}

The evolution of the physical and chemical properties of the aerosol was monitored with continuous and semi-continuous gas- and particle-phase instrumentation. Gas-phase measurements included: $\mathrm{CO}_{2}$ (LI-820, Li-Cor Biosciences), CO (Model 300A, API-Teledyne), $\mathrm{NO}_{\mathrm{x}}$ (Model 200A, APITeledyne) and $\mathrm{O}_{3}$ (Model 1008-PC, Dasibi). VOCs were measured with a Proton Transfer Reaction Mass Spectrometer (PTR-MS, Ionicon) and a semi-continuous Gas Chromatograph-Mass Spectrometer (GC-MS, based on the design of Millet et al., 2005). The PTR-MS and GC-MS systems were calibrated using standards (TO-15 Standard, Spectra Gases, a custom blend of light- and heavy hydrocarbons from Scott Gases, and vaporized toluene, acetone, acetonitrile and acetaldehyde). During the first experiment the PTR-MS was operated in full-scan mode (scanning from 22 to $142 \mathrm{amu}$ ). For subsequent experiments the PTR-MS was operated in selected-ion mode with a time resolution of $\sim 2.5 \mathrm{~min}$, only measuring ions that exhibited substantial changes in concentration during the first experiment. 
Aerosol size and composition distributions were measured with an Aerodyne Quadrapole Aerosol Mass Spectrometer (AMS, Canagaratna et al., 2007) and two Scanning Mobility Particle Sizers (SMPS, TSI, Inc., Models 3071 and 3080). The SMPS systems sampled particles with mobility diameters $\left(D_{m a}\right)$ from 16 to $760 \mathrm{~nm}$, overlapping with the AMS particle transmission window (Canagaratna et al., 2007). The AMS alternated every $10 \mathrm{~s}$ between mass spectrum (MS) scanning, Jump Mass Spectrum (JMS, Crosier et al., 2007) and particle time of flight (PToF) modes with a sample averaging time of 5 minutes and a vaporizer temperature of $600^{\circ} \mathrm{C}$. The AMS signal at $\mathrm{m} / \mathrm{z} 44$ was corrected for the contribution from gas-phase $\mathrm{CO}_{2}$. The particle-phase contribution at $m / z 28\left(\mathrm{CO}^{+}\right.$and potentially $\left.\mathrm{C}_{2} \mathrm{H}_{4}^{+}\right)$was estimated via comparison with particle-free samples (Grieshop et al., 2008). AMS data are used here to quantify organic aerosol concentration; detailed discussion of chemical composition measurements is contained in a companion paper (Grieshop et al., 2008).

Aerosol black carbon (BC) was measured with a Magee Scientific 7-channel aethalometer (Model AE-31). BC was quantified using either the 880 or $590 \mathrm{~nm}$ channel; these longer wavelengths are more strongly associated with $\mathrm{BC}$ than other light-absorbing (brown) carbonaceous species (Kirchstetter et al., 2004). There was no evidence of secondary production of light-absorbing aerosols at these wavelengths. Aethalometer attenuation measurements were corrected for particle loading effects using the method of Kirchstetter and Novakov (2007).

At the end of every experiment but one, filter packs containing two pre-fired quartz-fiber filters were collected and analyzed with a Sunset Laboratory TOT Organic Carbon/Elemental Carbon (OC/EC) Analyzer using a modified version of the NIOSH 5040 protocol (Subramanian et al., 2004). The back-up filter is used to correct the front filter for OC positive artifact from gas phase organics; see (Subramanian et al., 2004; Turpin et al., 2000). The aethalometer $\mathrm{BC}$ and filter EC concentrations were in good agreement $\left(R^{2}=0.99\right.$, slope $\left.=0.83\right)$. AMS organic and filter OC were well correlated $\left(R^{2}=0.97\right.$, slope $\left.=0.47\right)$, suggesting an organic-matter-to-organic-carbon ratio of the aged OA of about 2 .

Aerosol volatility was investigated using a thermodenuder (TD) system which heated a sample continuously drawn from the chamber and then stripped the evaporated vapors using an activated-carbon denuder (An et al., 2007). The residence time in the heated section was approximately $16 \mathrm{~s}$. The TD was operated at gas temperatures between 50 and $85^{\circ} \mathrm{C}$. An SMPS and the AMS were used to characterize the aerosol downstream of the TD and on a bypass line maintained at $25^{\circ} \mathrm{C}$. The measurements alternated between these two lines every 15-30 min. Total number loss in the TD system was found to be less than $2 \%$ at ambient temperatures (An et al., 2007) and AMS mass loss in the system (in bypass mode) was less than $5 \%$.

\subsection{Data analysis}

\subsubsection{Quantifying OA production}

Quantifying the production of OA requires correcting for losses of particles and vapors to the chamber walls. These corrections have been extensively discussed in earlier papers (Grieshop et al., 2007; Pierce et al., 2008; Weitkamp et al., 2007). In this paper we use two independent methods to quantify OA production. First, black carbon (BC) is used as a tracer for primary emissions. Under the assumption that the aerosol is internally mixed, $\mathrm{OA}$ and $\mathrm{BC}$ have the same wall-loss rate and changes in the ratio of $\mathrm{OA}$ to $\mathrm{BC}$ mass indicate condensation or evaporation of semi-volatile vapors. We quantify these changes using the OA enhancement ratio (ER):

$\mathrm{ER}(t)=\frac{\frac{\mathrm{OA}(t)}{\mathrm{BC}(t)}}{\frac{\mathrm{OA}\left(t=t_{0}\right)}{\mathrm{BC}\left(t=t_{0}\right)}}$

where $t_{0}$ refers to the time when the lights were turned on.

The second approach used to estimate OA production is based on correcting the SMPS data for wall losses. The firstorder wall-loss rate constant was measured at the beginning and end of each experiment when the black lights are off and there is no OA production. The OA production is then estimated based on a particle mass balance calculation. Additional details on this approach are discussed by Weitkamp et al. (2007).

Both approaches assume that the OA deposited to the walls remains in equilibrium with the suspended material. Evidence from other chamber aging and dilution experiments suggests that this is a reasonable assumption (Grieshop et al., 2007; Pierce et al., 2008; Weitkamp et al., 2007).

OA production can also be estimated by decomposing the AMS organic mass spectra (MS) into primary and secondary MS as outlined by Sage et al. (2008). This method and results from its application are discussed in the companion manuscript (Grieshop et al., 2008).

\subsubsection{OA volatility}

The AMS measurements made with the TD system were analyzed to quantify the OA volatility throughout the experiment. The organic aerosol mass that evaporated in the TD is presented as the mass fraction remaining (MFR), which is defined as the ratio of the OA mass concentration measured after the $\mathrm{TD}\left(\mathrm{C}_{\mathrm{TD}}\right)$ to that measured after the bypass line $\left(\mathrm{C}_{\text {bypass }}\right)$ :

$\mathrm{MFR}=\frac{\mathrm{C}_{\mathrm{TD}}}{\mathrm{C}_{\text {bypass }}}$ 


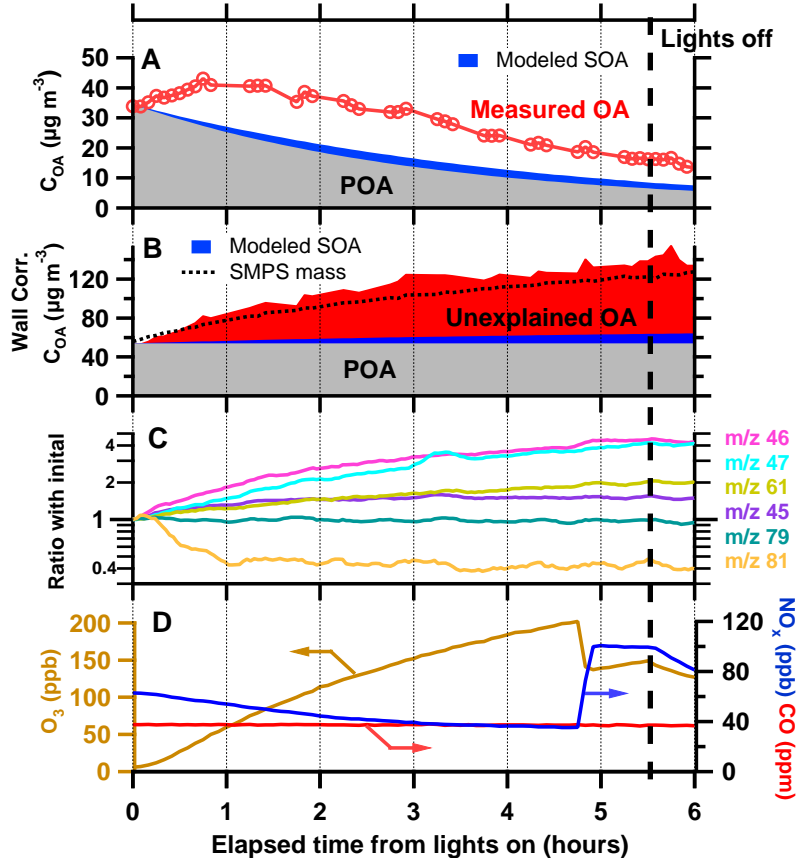

Fig. 1. Time series plots from aging experiment 5 conducted with emissions from smoldering Yellow Pine. (A) Measured OA, estimated POA based on BC data, and predicted traditional SOA. (B) Wall-loss-corrected OA concentrations of primary, predicted traditional SOA and total OA based on the BC data (red). The dashed line in (B) is the SMPS wall-loss-corrected estimate. (C) PTR-MS data showing the change in relative signal intensity for select mass fragments. (D) $\mathrm{CO}, \mathrm{O}_{3}$ and $\mathrm{NO}_{\mathrm{x}}$ levels. The large increase in $\mathrm{NO}_{\mathrm{x}}$ at hour 4.8 was due to an injection of additional NO into the chamber, which titrated some $\mathrm{O}_{3}$.

\subsubsection{SOA modeling}

The SOA model SOAM II was used to estimate the SOA production from traditional precursors (Koo et al., 2003; Strader et al., 1999; Weitkamp et al., 2007). For this work, SOAM II was further updated with recently measured higher SOA yields for the low- $\mathrm{NO}_{\mathrm{x}}$ photo-oxidation of aromatics (Ng et al., 2007). This update will maximize the calculated SOA contribution from traditional precursors.

Following the approach of Weitkamp et al. (2007), SOAM II was implemented as a box model which considers 13 lumped precursor species that represent 67 individual aromatic, alkane and alkene VOCs. The model uses the measured decay of these VOCs to generate condensable products; the partitioning of these products is calculated using absorptive partitioning theory under the assumption that the species are in equilibrium with the wall-loss corrected total aerosol mass concentration (Weitkamp et al., 2007).

We directly measured the decay of 10 traditional SOA precursors with the PTR-MS and GC-MS systems. This included the major aromatic and biogenic precursors such

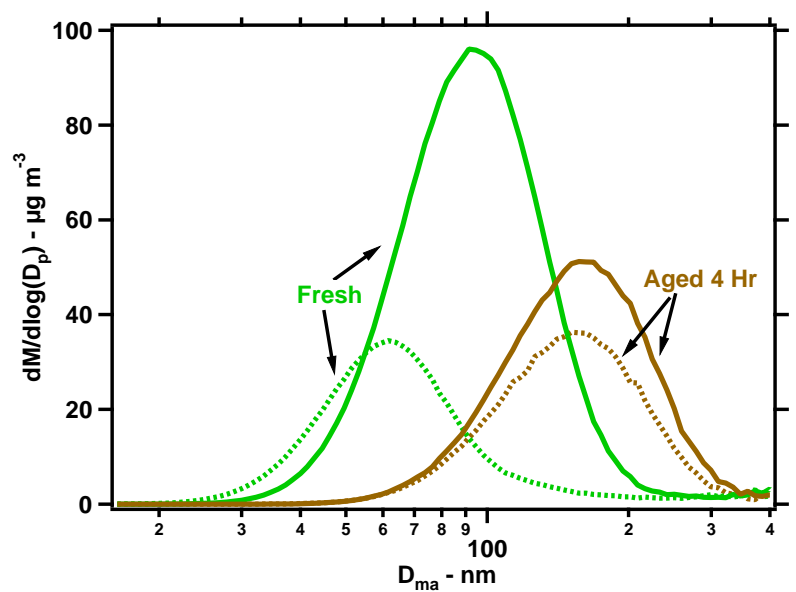

Fig. 2. SMPS mass-weighted particle size distributions measured before the UV lights were turned on (fresh) and after $4 \mathrm{~h}$ of aging. Dashed lines show size distributed measured after the aerosol was passed through the TD system at $50^{\circ} \mathrm{C}$. Calculations based on a particle density of $1 \mathrm{~g} \mathrm{~cm}^{-3}$.

as benzene, toluene, ethylbenzene, $\mathrm{m}$ - and o-xylenes and $\alpha$-pinene. Concentrations of other, minor SOA precursors were estimated by using emission ratios with both toluene and organic carbon emission factors from a published pine wood-combustion emission profile (Schauer et al., 2001). A comparison of emission ratios of compounds we measured indicates that this is a reasonable assumption. For example, Schauer's benzene-to-toluene emission ratio of 2.4 and methacrolein-to-toluene emission ratio of 0.15 are reasonably consistent with our campaign-average values of 4.8 and 0.12 , respectively. In some cases, unambiguious identification of a precursor was not possible - for example, xylenes, ethylbenzenes and benzaldehyde all appear at mass 107 in the PTR-MS and were not all separately calibrated for in the GC-MS. In such cases, VOC concentrations were attributed to the species with the highest SOA yields to give a conservative, upper-limit estimate for SOA production.

\section{Experimental results}

\subsection{Production of organic aerosol}

Figure 1 shows time-series of gas- and particle-phase data from a typical aging experiment. Figure 1a plots the OA concentration $\left(\mathrm{C}_{\mathrm{oa}}\right)$ measured with the AMS and an estimate of the POA mass based on the initial $\mathrm{C}_{\mathrm{OA}}$ and the wall-loss rate determined from the $\mathrm{BC}$ data. There is clear evidence of substantial production of OA. During the first hour of photooxidation, the production rate was greater than the wall-loss rate and the $\mathrm{C}_{\mathrm{OA}}$ increased by a factor of 1.3. After about an hour of oxidation, the secondary production slows and the OA level in the chamber falls due to wall loss. Particle size 
distributions measured with the SMPS are shown in Fig. 2. Before aging, the mass mode was around $90 \mathrm{~nm}$; after aging for four hours, it was about $190 \mathrm{~nm}$. The increase in the particle size was primarily driven by condensational growth.

Figure $1 \mathrm{~b}$ shows a time series of the wall-loss-corrected OA. The initial POA concentration was about $50 \mu \mathrm{g} \mathrm{m}^{-3}$; photo-oxidation increased the wall-loss-corrected OA concentration to approximately $130 \mu \mathrm{g} \mathrm{m}^{-3}$. These levels are consistent with near-source conditions and concentrations observed in concentrated plumes in the free troposphere associated with continental-scale transport of emissions from intense wildfires (e.g. OM $>75 \mu \mathrm{g} \mathrm{m}^{-3}$ after 1000s of $\mathrm{km}$ in Peltier et al., 2007). The AMS measurements indicate that the dominant component of the non-refractory primary and secondary aerosol is organic material, with minor contributions from nitrate (equivalent to $1-5 \%$ of the organic mass), ammonium ( 0.5 to $2 \%$ of the organic mass) and chloride $(<1 \%$ or organic mass).

The estimate of OA production shown in Fig. $1 \mathrm{~b}$ is based on the BC data measured with the aethalometer. This approach assumes that aethalometer response to $\mathrm{BC}$ loading does not change as the aerosol evolves during aging. The SMPS-based estimate of aerosol production provides a check on the BC-based estimate. Figure $1 \mathrm{~b}$ indicates that there is good agreement between these two independent approaches. These two estimates also compare favorably with estimates based on decomposition of the AMS spectrum presented in the companion manuscript (Grieshop et al., 2008). The consistency of these multiple independent estimates supports the use of the aethalometer data as a measure of the primary aerosol emissions.

Time series of selected PTR-MS mass fragments are plotted in Fig. 1c. For example, $m / z 81$ is associated with monoterpenes and rapidly decays to background levels within an hour. Benzene is detected at $m / z 79$; it decays very slowly during photo-oxidation. As discussed below, the measured decay of these and other traditional SOA precursors cannot explain the generation of OA observed in these experiments. Although the PTR-MS measurements were primarily used to quantify the decay of known SOA precursors, Fig. 1c also shows a few other mass fragments that exhibited large changes in multiple experiments. In every experiment, photo-oxidation substantially increased the PTR-MS signals at $\mathrm{m} / \mathrm{z} 31$ (formaldehyde), 46 (nitric acid), 47 (formic acid), and 59 (acetone, propanol, methyl vinyl ether, glyoxal or 2,3-butanedione). All of these tentative species designations are based upon previously published instrument intercomparison studies conducted with biomass-burning emissions (Christian et al., 2004; Karl et al., 2007). Across the set of experiments, the PTR-MS signal at $m / z 31$ increased by a factor of 1.5 to 2.1 ; the signals at $m / z 46$ and $m / z 47$ increased by 2.5 to 7.5 times; and the signal at $\mathrm{m} / \mathrm{z} 59$ increased by a factor of 1.2 to 2.2. Other masses with increased signal in more than one experiment were $\mathrm{m} / \mathrm{z} 43$ (potentially propene, but also $\mathrm{CH}_{3} \mathrm{CO}^{+}$and $\mathrm{C}_{3} \mathrm{H}_{7}^{+}$fragments, Christian et al., 2004), 45 (acetalaldehyde) and 61 (acetic acid and glycolaldehyde). Acetic acid production was observed downwind of African savannah fires (Hobbs et al., 2003) but not in plumes from boreal fires (de Gouw et al., 2006) and is not predicted by photochemical plume models (Trentmann et al., 2005).

Measured $\mathrm{O}_{3}, \mathrm{NO}_{\mathrm{x}}$ and $\mathrm{CO}$ concentrations are shown in Fig. 1d. $\mathrm{O}_{3}$ levels in this experiment increased by about $200 \mathrm{ppb}$ and $\mathrm{NO}_{\mathrm{x}}$ concentration dropped from 63 to $35 \mathrm{ppb}$ during aging. These changes are qualitatively consistent with both field measurements (Hobbs et al., 2003) and plume model simulations (Trentmann et al., 2003). The ozone concentrations are somewhat higher than might be seen in a real plume due to the lack of continued dilution in the chamber. $\mathrm{CO}$ is often used as tracer in plume measurements; Fig. 1d indicates that $\mathrm{CO}$ levels were constant throughout the experiment.

Hydroxyl radical $(\mathrm{OH})$ concentrations were inferred from the measured decay of multiple light aromatics and published kinetics data. For the experiment shown in Fig. 1, the average $\mathrm{OH}$ concentration was $4( \pm 3) \times 10^{6}$ molecules $\mathrm{cm}^{-3}$, comparable to daytime conditions in the summer. $\mathrm{OH}$ concentrations were reasonably constant throughout the experiment.

Figure 1a and $\mathrm{b}$ also shows an estimate of traditional SOA based on the measured precursor decay and SOAM II. This estimate only explained $15 \%$ of the observed OA increase. Light aromatics were the most important traditional precursors, contributing $70 \%$ of the predicted SOA mass. As illustrated in Fig. 1c, the oxidation rate of light aromatics was much too slow to explain the rapid initial increase in OA concentrations. For example, the initial benzene concentration in this experiment was $4 \mathrm{ppb}$ but only $13 \%$ of it was oxidized after $5.5 \mathrm{~h}$ of aging. The initial toluene concentration was $1 \mathrm{ppb}$ but only $30 \%$ of it was oxidized during this experiment. Monoterpenes contributed only $20 \%$ of the predicted SOA formation. It seems highly unlikely that uncertainty in SOA yields from traditional precursors could explain the large amounts of unaccounted-for OA production.

Although Fig. 1 features data from one experiment, similar results were observed in other experiments conducted with emissions from smoldering and flaming soft- and hardwood fires. Table 1 summarizes the combustion conditions for the entire set of experiments. Modified combustion efficiencies (MCE, Koppmann et al., 2005) ranged between 0.58 and 0.93 with a median value of 0.87 . Reid et al. (2005) uses an MCE value of 0.9 to differentiate between flaming (high MCE) and smoldering (lower MCE) combustion; based on this definition, four of these experiments were performed with emissions from smoldering combustion while two were from flaming combustion. OC-to-EC ratios also depend on combustion conditions. The two experiments with the lowest MCE values (smoldering fires) are OC-dominated while flaming combustion produces substantially more EC. 
Table 1. Summary of experimental conditions of fresh emissions before turning on the UV lights.

\begin{tabular}{|c|c|c|c|c|c|c|c|c|c|c|}
\hline \multirow{2}{*}{\multicolumn{2}{|c|}{ Experiment }} & $\mathrm{MCE}^{\mathrm{a}}$ & POA & OC:EC & $\mathrm{NO}_{\mathrm{x}}^{\mathrm{b}, \mathrm{c}}$ & $\mathrm{CO}^{\mathrm{c}}$ & $\begin{array}{l}\mathrm{CO} / \\
\mathrm{CO}_{2}^{\mathrm{c}} \\
\end{array}$ & $\begin{array}{c}\text { Benzene/ } \\
\mathrm{CO}^{\mathrm{c}}\end{array}$ & $\begin{array}{c}\text { Toluene/ } \\
\mathrm{CO}^{\mathrm{c}}\end{array}$ & $\begin{array}{c}\text { Acetonitrile/ } \\
\mathrm{CO}^{\mathrm{c}, \mathrm{d}}\end{array}$ \\
\hline & & & $\mu \mathrm{g} \mathrm{m}^{-3}$ & ratio & $\mathrm{ppb}$ & ppm & molar \% & $\mathrm{ppb}_{\mathrm{ppm}}{ }^{-1}$ & $\mathrm{ppbppm}^{-1}$ & $\mathrm{ppb}_{\mathrm{ppm}}{ }^{-1}$ \\
\hline 1 & $\begin{array}{l}\text { Laurel Oak } \\
\text { smoldering and flaming }\end{array}$ & 0.85 & 40 & 1.6 & 113 & 19 & 17 & 0.8 & 0.2 & 0.1 \\
\hline 2 & flaming w/embers & 0.93 & 90 & 1.9 & 150 & 13 & 7 & 1.3 & 0.2 & 0.3 \\
\hline 3 & $\begin{array}{l}\text { smoldering and flaming } \\
\text { Yellow Pine }\end{array}$ & 0.90 & 40 & 1.1 & 60 & 6 & 11 & 1.1 & 0.1 & 0.5 \\
\hline 4 & flaming w/embers & 0.88 & 770 & 2.2 & $103(39)$ & 10 & 14 & 4.3 & 1.5 & 0.6 \\
\hline 5 & $\begin{array}{l}\text { smoldering/dying flame } \\
\text { High } \mathrm{NO}_{\mathrm{x}}(\text { Pine) }\end{array}$ & 0.71 & 50 & 13 & 63 & 37 & 41 & 0.1 & 0.0 & 0.1 \\
\hline 6 & flaming w/embers & 0.58 & 70 & 13 & 244 (18) & 2 & 71 & 3.7 & 1.1 & 0.8 \\
\hline
\end{tabular}

${ }^{\mathrm{a}} \mathrm{MCE}=$ Modified Combustion Efficiency, see (Koppmann et al., 2005) for definition.

$\mathrm{b}$ The values in parenthesis for experiments 4 and 6 show the $\mathrm{NO}_{\mathrm{x}}$ levels before additional NO was injected into the chamber.

c All gas-phase data are background-corrected.

${ }^{\mathrm{d}}$ Uncertainty in acetonitrile concentrations were about a factor of 2 due to problems with the calibration for this compound during these experiments.

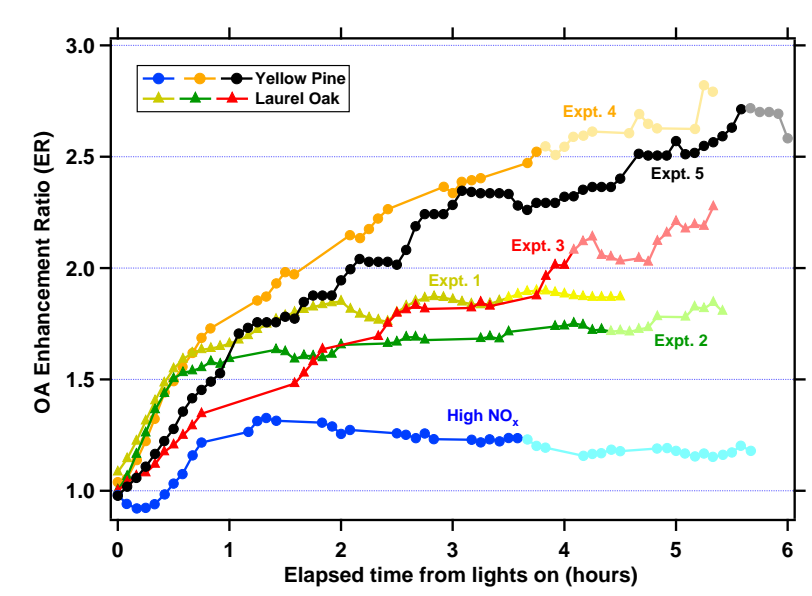

Fig. 3. Compilation of OA ER calculated using AMS and BC data (Eq. 1). The traces are shown in a lighter color after the chamber UV lights were turned off. Experimental conditions are listed in Tables 1 and 2.

Figure 3 plots OA ER calculated using the $\mathrm{BC}$ approach from all of the experiments. Excluding one high- $\mathrm{NO}_{\mathrm{x}}$ experiment discussed below, the OA ER ranged between 1.8 and 2.7 after 4 to $6 \mathrm{~h}$ of aging. These estimates also agree with results from spectral decomposition of the AMS data (Grieshop et al., 2008). Although experiments were conducted with different fuels and combustion conditions, we did not see any general correlation between OA production and MCE or OC-to-EC ratio. Traditional SOA is predicted to contribute only a small fraction of the observed OA production in every experiment. Table 2 indicates that in the five low- $\mathrm{NO}_{\mathrm{x}}$ experiments, modeled SOA production contributed on average $17 \%$ of the total SOA production (range 5-30\%).
Oxidant levels in the chamber were comparable to daytime conditions during the summer. The estimated campaign-average $\mathrm{OH}$ concentration was 3.6 $( \pm 0.5) \times 10^{6}$ molecules $\mathrm{cm}^{-3} \quad( \pm$ standard deviation of experiment mean estimates). $\mathrm{O}_{3}$ production occurred throughout the "lights-on" period in every experiment. Figure 3 indicates that, in some experiments, OA production continued after the UV lights were turned off. This may be due to continued ozone chemistry; ozone levels declined after the lights were turned off (first order decay of $0.24 \pm 0.16 \mathrm{ppb} \mathrm{h}^{-1}$ ). However, no OA production was observed in the period before the UV lights were turned on (typically $30-45 \mathrm{~min}$ after injection).

Much less OA was produced in one experiment in which $220 \mathrm{ppbv}$ of NO was added to the chamber before turning on the UV lights. This experiment is labeled as high $\mathrm{NO}_{\mathrm{x}}$ in Fig. 3. The chemistry for this experiment appeared to be fundamentally different than any of the other experiments. For example, after adding the $\mathrm{NO}, \mathrm{O}_{3}$ concentrations dropped for about an hour indicating titration. In addition, Fig. 3 shows that the OA ER initially decreased after the lights were turned on, presumably due to evaporation. This suggests that OA production from photo-oxidation of wood smoke depends on the VOC-to- $\mathrm{NO}_{\mathrm{x}}$ ratio. Such dependence has been observed for traditional SOA precursors due to peroxy radical chemistry ( $\mathrm{Ng}$ et al., 2007; Presto et al., 2005b). However, $\mathrm{NO}_{\mathrm{x}}$ levels in this experiment were likely much higher than typical fire plumes: the $\mathrm{NO}_{\mathrm{x}}$-to-benzene and toluene ratios in this experiment were a factor of 5 to 100 higher than typical plumes (Andreae and Merlet, 2001). In addition, chamber $\mathrm{CO}$ and $\mathrm{CO}_{2}$ levels were much lower during this experiment, potentially indicating a problem with the sampling system. 
Table 2. Summary of experimental parameters related to aerosol aging.

\begin{tabular}{|c|c|c|c|c|c|c|c|}
\hline & \multirow[t]{2}{*}{ Experiment } & \multirow{2}{*}{$\frac{(\mathrm{OH}]}{\operatorname{molec~} \mathrm{cm}^{-3}}$} & \multirow{2}{*}{$\frac{\Delta \mathrm{O}_{3}^{\mathrm{a}}}{\mathrm{ppb}}$} & \multirow{2}{*}{$\frac{\mathrm{BC}-\mathrm{OA} \mathrm{ER}^{\mathrm{b}}}{\text { ratio }}$} & \multirow{2}{*}{$\frac{\text { SOAM ER }^{\mathrm{c}}}{\text { Ratio }}$} & \multicolumn{2}{|c|}{ AMS O:C $\mathrm{C}^{\mathrm{d}}$} \\
\hline & & & & & & initial & final \\
\hline 1 & $\begin{array}{l}\text { Laurel Oak } \\
\text { smoldering and flaming }\end{array}$ & $4.2 \mathrm{E}+06$ & 148 & 1.9 & 1.16 & 0.36 & 0.56 \\
\hline 2 & flaming w/embers & $3.6 \mathrm{E}+06$ & 275 & 1.8 & 1.24 & 0.34 & 0.55 \\
\hline 3 & $\begin{array}{l}\text { smoldering and flaming } \\
\text { Yellow Pine }\end{array}$ & $3.6 \mathrm{E}+06$ & 102 & 2.1 & 1.21 & 0.25 & 0.42 \\
\hline 4 & flaming w/embers & $3.1 \mathrm{E}+06$ & 220 & 2.6 & 1.08 & 0.13 & 0.38 \\
\hline 5 & $\begin{array}{l}\text { smoldering/dying flame } \\
\text { High } \mathrm{NO}_{\mathrm{x}} \text { (Pine) }\end{array}$ & $3.9 \mathrm{E}+06$ & 196 & 2.7 & 1.25 & 0.2 & 0.5 \\
\hline 6 & flaming w/embers ${ }^{\mathrm{e}}$ & $2.9 \mathrm{E}+06$ & 43 & 1.2 & 1.15 & 0.22 & 0.4 \\
\hline
\end{tabular}

a $\Delta \mathrm{O}_{3}$ is the increase in chamber $\mathrm{O}_{3}$ mixing ratio during the photo-oxidation phase of the expeirment.

${ }^{b}$ BC-OA ER is the end-of-experiment OA ER determined using BC-scaling (Eq. 1).

${ }^{c}$ SOAM ER is the predicted OA ER due to traditional SOA formation calculated using the measured VOC precursor decay and SOAM II.

$\mathrm{d}$ AMS O:C ratio is determined using the fractional contribution at $m / z 44$ to the AMS organic spectrum and the relation from Aiken et al. (2008).

${ }^{\mathrm{e}}$ High- $\mathrm{NO}_{\mathrm{x}}$ yields from $\mathrm{Ng}$ et al. (2007) were used to model SOA formation from aromatics in this experiment.

\subsection{Organic aerosol volatility}

The volatility of the OA was characterized using a thermodenuder (TD). Figure 2 plots particle volume distributions measured before and after the TD with the SMPS. The shifts in these distributions indicate that a large fraction of both the fresh and aged aerosol evaporated at $50^{\circ} \mathrm{C}$.

To quantify the changes in OA mass with temperature, Fig. 4a shows the MFR of fresh and aged OA measured with the AMS as a function of TD temperature (a plot referred to here as a thermogram). Between $50 \%$ and $80 \%$ of the fresh POA evaporated at $50^{\circ} \mathrm{C}$. Therefore, the majority of wood smoke POA should be classified as semivolatile at typical atmospheric conditions, consistent with recent dilution sampler (Lipsky and Robinson, 2006; Shrivastava et al., 2006) and thermodenuder measurements (Huffman, et al., 2008).

The aged OA was always less volatile than freshly emitted POA. For example, Fig. 4a indicates that only 20 to $40 \%$ of the aged $\mathrm{OA}$ mass evaporated at $50^{\circ} \mathrm{C}$ in our TD. Such a shift is consistent with photo-oxidation creating more oxygenated but less volatile compounds. Aging increased the AMS $m / z$ 44 signal $\left(\mathrm{CO}_{2}^{+}\right)$, indicating that the OA becomes progressively more oxygenated (Grieshop et al., 2008).

The changes in OA volatility as a function of time are shown in Fig. 5. In every experiment, the OA volatility measured at $50^{\circ} \mathrm{C}$ decreased substantially during the first hour of photo-oxidation, but then remained essentially constant with subsequent aging. This step-change-like behavior means that the OA formed during the initial stages of photo-oxidation is much less volatile than the POA. However, the constant volatility after one hour of aging is somewhat surprising considering that there was sustained production of OA in every experiment (Fig. 3) and that the AMS data indicates that OA becomes progressively more oxygenated as the experiment progresses (Grieshop et al., 2008). The trends in the OA composition and volatility data may indicate that fragmentation becomes more important after the initial stages of aging.

One must carefully consider whether or not the aerosol reaches equilibrium when interpreting TD data (An et al., 2007). If the OA is not in equilibrium then the TD data provide a measure of the relative evaporation rates, which depend on particle size and concentration (Seinfeld, 1998). The increase in particle size due to condensational growth will slow evaporation, potentially biasing our interpretation that the aged OA is less volatile than the POA. A dynamic mass transfer model of the aerosol inside the TD indicates that the measured changes in particle size were insufficient to cause a substantial change in particle equilibration time (Stanier et al., 2007). We suggest two potential explanations for the step-change in particle volatility: 1) time-varying OA composition (as discussed above); or 2) evolving mass-transfer limitations, either due to accommodation at the particle surface or other uptake processes, which limit the evaporation of the bulk aerosol. As described in the companion manuscript (Grieshop et al., 2008), TD data for individual AMS fragments provides some evidence to support the latter explanation, but further investigation is needed.

\section{Basis-set modeling}

In this section we compare our data to predictions of the model of Robinson et al. (2007) to investigate the hypothesis that the unaccounted-for OA production is due to oxidation of low-volatility organic vapors. This hypothesis is 

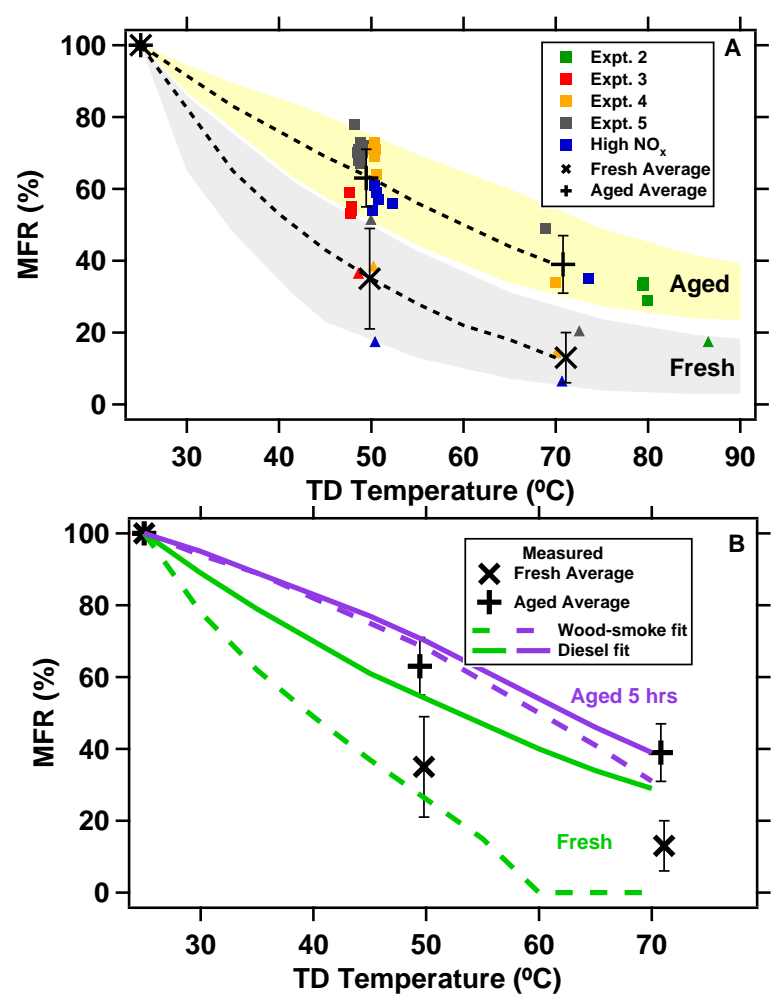

Fig. 4. Thermograms of OA mass fraction remaining (MFR) for fresh and aged aerosols. (A) Measured data for five experiments. Data points for fresh OA are shown with triangles and aged OA with squares. The dashed lines in (A) indicate average fresh and aged thermograms. The colored fans in (A) illustrate the interexperiment variability in the thermodenuder data. (B) Comparison of average measured OA MFR values with equilibrium predicted values based on modified aging model output as discussed in the text. Dashed and solid lines show model predictions using the "wood-smoke" and "diesel" fits shown in Fig. 6, respectively. Lower (green) traces show predicted volatility of fresh emissions while upper (purple) traces show volatility after $5 \mathrm{~h}$ of aging.

motivated by several pieces of evidence. First, wood smoke contains thousands of individual organic compounds, distributed across a wide range of volatilities. Source dilution experiments have shown that a large fraction of wood smoke POA evaporates upon isothermal dilution (Lipsky and Robinson, 2006; Shrivastava et al., 2006), which means that a substantial pool of low-volatility organic vapors exists in plumes (and our chamber). Second, oxidation of these vapors will produce acids, nitrates, and carbonyls, which have lower vapor pressures than the parent compounds (Pankow and Asher, 2008). Given the low initial volatility of the parent compounds, we expect oxidation of these vapors to form OA with high efficiency; for example, SOA yields from n-alkanes increase with carbon number (Lim and Ziemann, 2005).

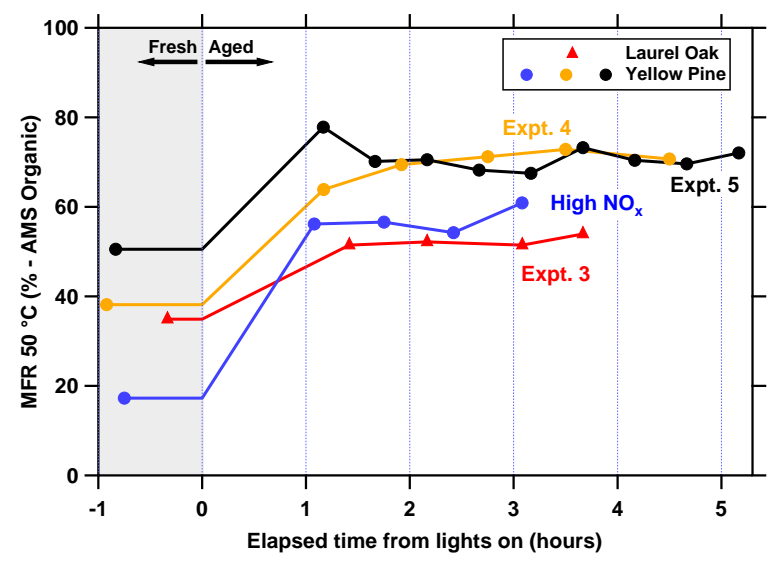

Fig. 5. Time series of OA MFR measured at $50^{\circ} \mathrm{C}$ for four wood smoke aging experiments. Lines connecting data points are intended to guide the eye.

The model is described in detail by Robinson et al. (2007) and Shrivastava et al. (2008). Table 3 summarizes the input parameters, most of which are from Robinson et al. (2007). Model predictions based on different sets of input parameters are compared to highlight important uncertainties. The model is based on the volatility basis-set framework (Donahue et al., 2006), which was implemented in a box model. The model tracks the concentration of low-volatility organics using a nine-bin volatility basis set; the bins have effective saturation concentrations $\left(\mathrm{C}^{*}\right)$ which are spaced by factors of 10 between 0.01 and $10^{6} \mu \mathrm{g} \mathrm{m}^{-3}$ at $298 \mathrm{~K}$. Gas-particle partitioning is calculated using absorptive partitioning theory (Pankow, 1994) assuming that all of the organics form a quasi-ideal solution and that the bulk gas and particle phases are in equilibrium.

The initial gas and particle concentrations in each bin were determined based on the measured POA concentrations and an assumed volatility distribution. For this work we considered three different volatility distributions, which are plotted in Fig. 6a and listed in Table 3. Two of the distributions were proposed by Robinson et al. (2007) to represent POA emissions. These distributions were based on the measured gas-particle partitioning of diesel exhaust. The distribution labeled "Diesel" is based on partitioning of the organics collected on quartz filters; the distribution labeled "Diesel+IVOC" includes additional emissions of intermediate volatility organic compounds (IVOCs) that are presumably not captured on the quartz filters (see Robinson, 2007, for details on these volatility distributions). The third distribution, labeled "wood smoke," was derived by fitting previously published wood-smoke dilution data collected at moderate- to high-concentrations using quartz filters (Lipsky and Robinson, 2006; Shrivastava et al., 2006).

Figure $6 \mathrm{~b}$ compares the gas-particle partitioning predicted by these three distributions with partitioning data for wood smoke measured with dilution samplers (Lipsky and 
Table 3. Parameters used in basis-set and thermodenuder models.

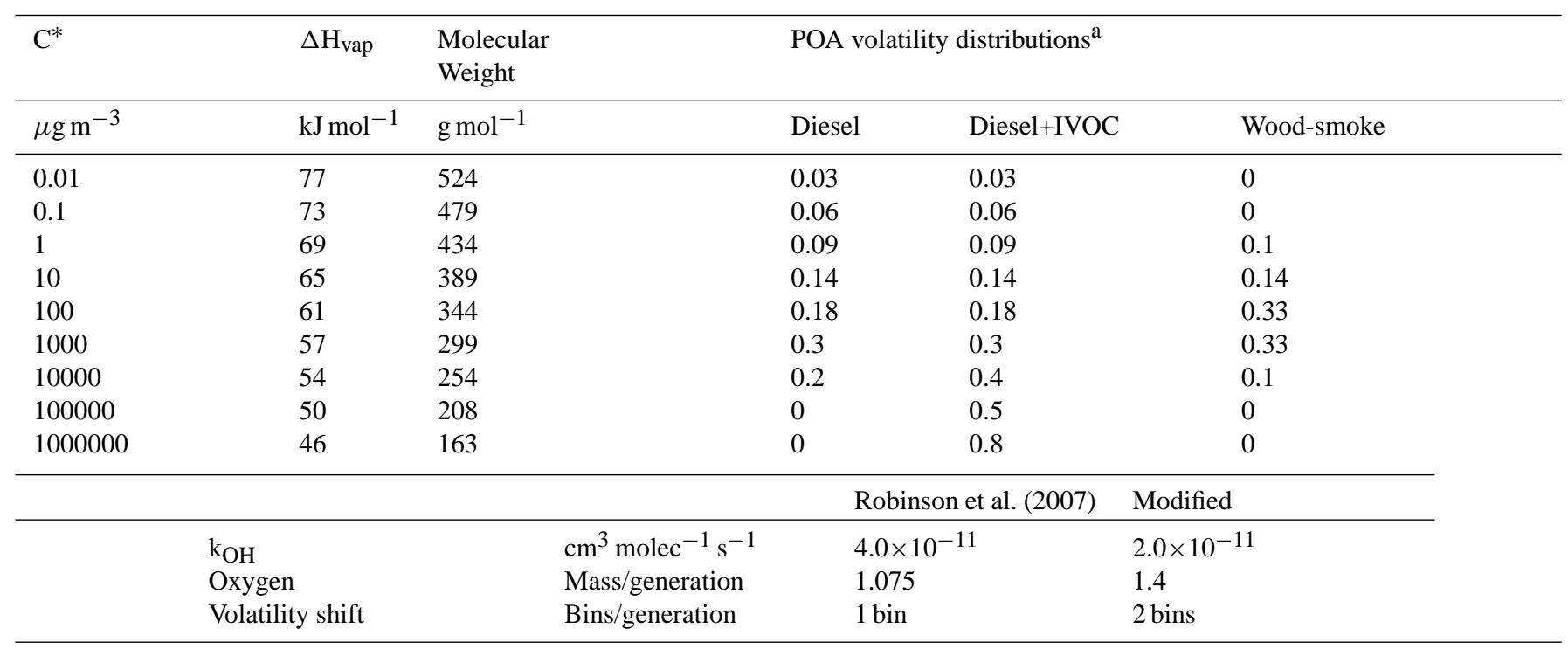

${ }^{\text {a }}$ Relative mass emissions in each volatility bin.

Robinson, 2006; Shrivastava et al., 2006). The predicted gas-particle partitioning based on all three distributions agrees well with the experimental data, justifying their use in our simulations. It also supports the approach of Robinson et al. (2007) to use one distribution to represent all POA emissions.

After determining the initial concentrations of lowvolatility organics, the model simulates aging by reacting the vapors with $\mathrm{OH}$. Following Robinson et al. (2007), the $\mathrm{OH}$ reaction rate constant $\left(k_{\mathrm{OH}}\right)$ is $4 \times 10^{-11} \mathrm{~cm}^{3} \mathrm{molec}^{-1} \mathrm{~s}^{-1}$ (slightly higher than that expected for the $\mathrm{OH}$ oxidation of a large $n$-alkane) and the scheme assumes a modest (7.5\%) net increase in mass per reaction to account for added oxygen (equivalent to adding a single oxygen atom to a $\mathrm{C}_{15}$ alkane). Each reaction reduces the volatility of the vapors by a factor of ten (i.e. shifts the material to the next lower volatility bin), which changes the gas-particle partitioning and creates new OA.

Figure 7 compares model predictions to the average data from the five low- $\mathrm{NO}_{\mathrm{x}}$ experiments. For these calculations, the model was initialized using the average POA concentrations and the chemistry was driven by the average $\mathrm{OH}$ concentrations. The experimental data were used to evaluate the predicted OA production (Fig. 7a), changes in OA composition (Fig. 7b), and OA volatility (Fig. 7c).

Figure 7 a compares model predictions to the average OA enhancement ratio (ER). In this plot, the measured ER has been corrected for the predicted SOA production from traditional precursors; therefore it only represents the unaccounted-for OA production. Simulations using either the "diesel" or "wood smoke" volatility distribution reproduce the measured OA production. The "wood smoke" predictions are not shown in Fig. 7a to reduce clutter; they essentially fall on top of the diesel calculations. Therefore, there is sufficient mass of low-volatility vapor to explain the observed production. However, the model based on the "diesel+IVOC" distribution outpaces the observed production after about $2 \mathrm{~h}$ of aging. Likely explanations are that this model overestimates the concentrations of IVOC vapors and/or that the aging mechanism is not appropriately altering the volatility distribution. The comparisons in Shrivastava et al. (2008) suggest that wood combustion emits relatively less IVOC mass than motor vehicles, lending support to the first concern. Furthermore, the aging mechanism assumes that the reaction products all have lower volatility than the precursors; however, this may not be a good assumption for IVOC vapors, which only form aerosols after multiple generations of processing. The probability that the carbon backbone breaks to create more volatile products should increase with each generation of processing.

Figure 7a indicates that none of the models reproduce the initial rapid burst of OA production that occurs in the first hour of aging. This suggests that there may initially be a pool of very reactive precursors.

The measured OA composition data provide another test of the basis-set model. As described in the companion manuscript (Grieshop et al., 2008), the AMS data indicate that aging continuously increases the amount of oxygenated OA. Figure $7 \mathrm{~b}$ shows the average O:C ratio calculated for the five low- $\mathrm{NO}_{\mathrm{x}}$ experiments using the AMS signal at $\mathrm{m} / \mathrm{z}$. $44\left(\mathrm{CO}_{2}^{+}\right)$and the parameterization of Aiken et al. (2008). An O:C ratio can also be inferred from the basis set model 

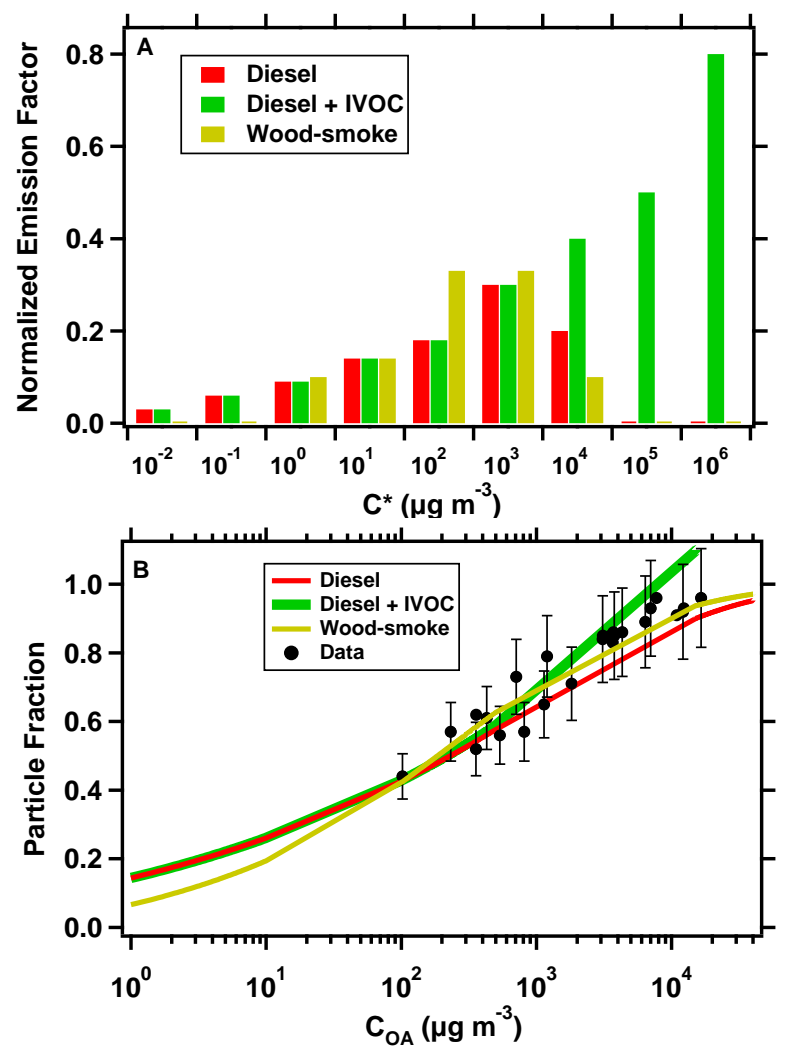

Fig. 6. (A) Volatility distributions proposed by Robinson et al. (2007) for POA along with a fit to wood-smoke dilution data. (B) Measured gas-particle partitioning data for wood-smoke expressed as the fraction of the semivolatile organics existing in the particle phase. The curves in (B) show predicted partitioning based on volatility distributions shown in (A). Measured partitioning data from (Lipsky and Robinson, 2006; Shrivastava et al., 2006).

based on the assumed $7.5 \%$ increase in mass per generation. The initial O:C ratio in the model is based on the experiment average for the POA.

Figure 7b indicates that the Robinson et al. (2007) model only increases the predicted O:C ratio from 0.32 to 0.38 after $4 \mathrm{~h}$ of aging versus an average measured increase of 0.32 to 0.48 . Therefore, it does not add enough oxygen to the OA. We modified the model parameters to better fit the observed increase in $\mathrm{O}: \mathrm{C}$ ratio. The modified aging mechanism reduces the volatility of gas-phase material by a factor of 100 with each generation of oxidation (a two-bin shift), the $\mathrm{OH}$ reaction rate was halved to $2 \times 10^{-11} \mathrm{~cm}^{3} \mathrm{molec}^{-1} \mathrm{~s}^{-1}$ and the organic mass was increased by $40 \%$ for each generation of oxidation (equivalent to adding about 5 oxygen atoms to a $\mathrm{C}_{15}$ alkane). As shown in Fig. 7a these modifications have little effect on the predicted OA production; however, they improve the predictions of OA oxygen content.
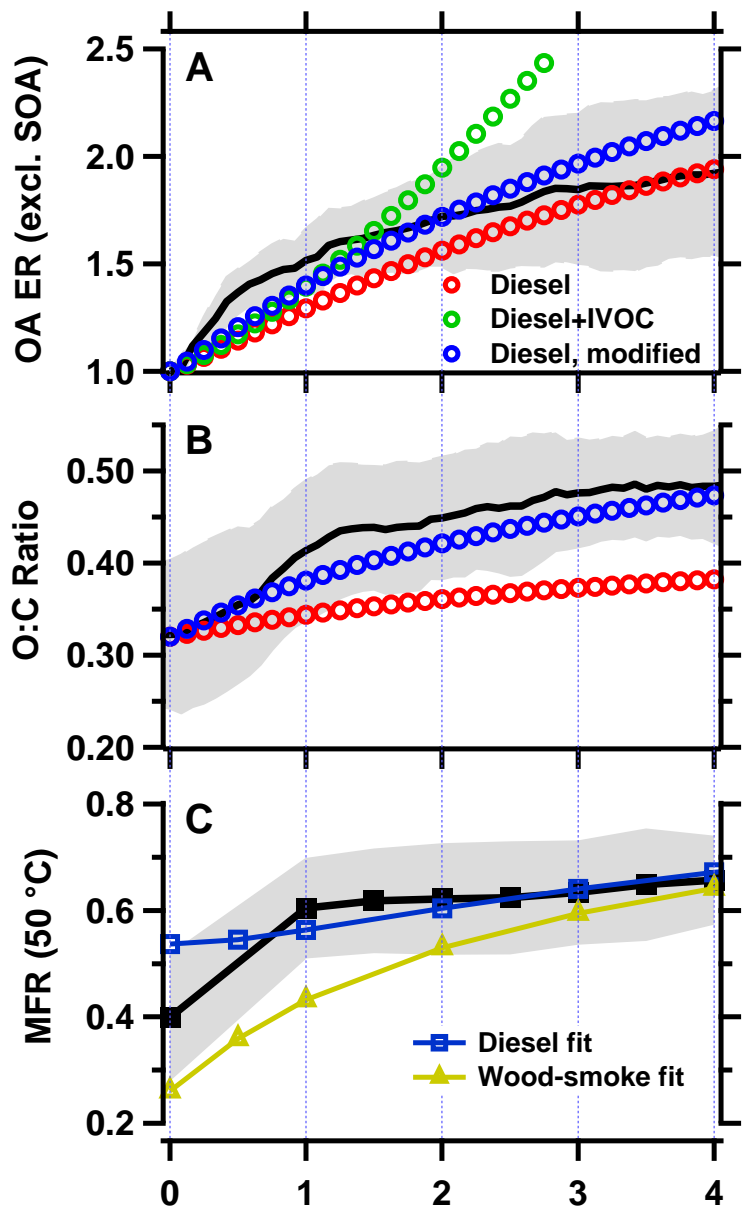

Elapsed time from lights on (hours)

Fig. 7. Time series comparing campaign-average measured and predicted OA: (A) Enhancement ratio corrected for traditional SOA; (B) OA O:C ratio; (C) OA MFR at $50^{\circ} \mathrm{C}$. Black lines indicate average data with grey regions showing \pm one standard deviation. The colors of the lines and symbols are used consistently in all three panels; the symbols indicate model predictions using the different sets of parameters listed in Table 3. Curves in (C) indicate predicted evaporation at equilibrium in the TD using diesel and wood-smoke volatility distributions in the modified aging model. Models based on the wood-smoke and diesel volatility distributions have nearly identical predicted OA ER and O:C time series.

The modified aging parameters are reasonably consistent with what is known about the chemistry of large hydrocarbons. For example, a reduction of $\mathrm{C}^{*}$ by a factor of 100 per generation of oxidation is supported by the effects on volatility of additional molecular functionality (Pankow and Asher, 2008). However, the amount of added oxygen per generation is somewhat higher than what would be expected; for example, the mechanism of Lim and Ziemann (2005) adds up to four oxygen atoms per generation. A potential explanation is that fragmentation reactions that break the carbon backbone may play an important role in the photochemical aging of primary emissions. Reducing the size of the carbon backbone 
will lead to more rapid increases in $\mathrm{O}: \mathrm{C}$ while also limiting the overall OA growth due to volatilization of the lighter fragments. It thus has the potential to explain the sharp initial increase in $\mathrm{OA}$, the sharp initial decrease in volatility, and the progressive increase in particle-phase $\mathrm{O}: \mathrm{C}$.

The OA volatility measurements made with the TD provide a final test of the model. In order to compare the model predictions to the data, we calculated the OA MFR as a function of temperature using simulated volatility distributions. The temperature dependence of $\mathrm{C}^{*}$ is expressed using the Clausius-Clapeyron equation and the enthalpies of vaporization listed in Table 3. These values are based on data for large saturated species commonly found in primary emissions (Donahue et al., 2006). The calculations assume that the aerosol reaches equilibrium in the TD, an assumption discussed in more detail below.

Figure $4 \mathrm{~b}$ indicates that the model based on the diesel volatility distribution under-predicts the evaporation of the fresh POA. This model also only predicts a relatively minor decrease in volatility with aging, far less than was observed in the experimental data (Fig. 7c). Considering that this model assumes equilibrium TD partitioning (and thus likely over-predicts evaporation relative to the experimental data), this result indicates that the diesel distribution assigns too much material to the lowest volatility bins to accurately represent the partitioning behavior of wood-smoke aerosols in the TD.

Much better agreement is observed with the TD data when the wood-smoke volatility distribution is used in the aging and TD models. For example, thermograms in Fig. 4b show that the wood-smoke distribution becomes substantially less volatile after $5 \mathrm{~h}$ of aging, consistent with the experimental data. In addition, the model calculations with the wood-smoke distribution generally show more evaporation than was observed, consistent with the measured aerosol not reaching equilibrium in the TD.

Figure 6 indicates that the wood smoke and diesel volatility distributions are quite similar except in the lowest $\mathrm{C}^{*}$ bins. Therefore, the predictions of the TD model appear to be quite sensitive to the amount of material assigned to these bins, which is currently not well-constrained with experimental data (Shrivastava et al., 2006).

\section{Discussion and conclusions}

Photo-oxidation of dilute wood combustion emissions in a smog chamber rapidly produces substantial OA, greatly in excess of what can be explained by the measured decay of traditional SOA precursors. The rate and magnitude of the OA production in our experiments is consistent with field observations of aerosol mass production downwind of large fires (Reid et al., 2005). For example, Lee et al. (2008) report 1.5 to 6 -fold enhancements of OA concentrations after 3 to $4 \mathrm{~h}$ of aging downwind of a prescribed burn in Georgia.
Substantial OA production from fire emissions may help explain carbon-isotope studies indicating that modern carbon is often the dominant contributor to OA, even in urban areas (Hildemann et al., 1994; Szidat et al., 2006; Tanner et al., 2004; Zheng et al., 2006).

Field studies have attributed OA production in fire plumes to slow condensation of large hydrocarbons (Reid et al., 1998), enhanced isoprenoid emissions (Lee et al., 2008) and acid-catalyzed reactions (Nopmongcol et al., 2007). However, none of these mechanisms appear to explain our experimental data. Partitioning theory and dilution sampler measurements indicate that large hydrocarbons do not condense but evaporate as the plume isothermally disperses at atmospheric temperatures (Lipsky and Robinson, 2006; Shrivastava et al., 2006). Heating of the forest canopy and combustion of a wider range of fuels can lead to enhanced emissions of isoprenoids such as monoterpenes, but in our experiments these emissions were almost two orders of magnitude too low to explain the observed OA production. Finally, the lack of inorganic acidity likely reduces the potential for acidcatalyzed reactions in our experiments.

We attribute the production of the unexplained OA to the oxidation of low-volatility organic vapors. The existence of these vapors is demonstrated by wood smoke POA evaporating upon isothermal dilution. The concentrations of these low-volatility vapors appear to greatly exceed that of POA at atmospheric conditions (Lipsky and Robinson, 2006; Shrivastava et al., 2006, 2008), consistent with the observed doubling or tripling OA concentrations after modest amounts of aging of diluted emissions in a smog chamber. A challenge is that the chemical identity of the vast majority of low-volatility organics is not known because they appear as an unresolved complex mixture (UCM) in traditional gaschromatographic analysis (Schauer et al., 2001). The volatility basis-set approach provides a semi-empirical framework to treat the partitioning and aging of this complex mixture. The success of the basis-set model in simulating the OA production is encouraging, but the model-measurement comparison indicates that more research is needed to accurately represent the volatility and aging of primary emissions. Important uncertainties include the emissions of IVOCs, fragmentation in the aging mechanism, and the rapid increases in $\mathrm{OA}$ oxygen content.

The thermodenuder data provide new insight into OA volatility. They demonstrate that fresh POA is more volatile than the aged OA produced from photo-oxidation. This is in contrast to the current treatment in chemical transport models, which assumes that POA is non-volatile and SOA is semivolatile. The fact that the aged OA is less volatile than the POA is consistent with low-volatility vapors being important SOA precursors. In other words, oxidation of low-volatility vapors should likely create products that are even less volatile than semivolatile POA or traditional SOA formed from very volatile precursors. 


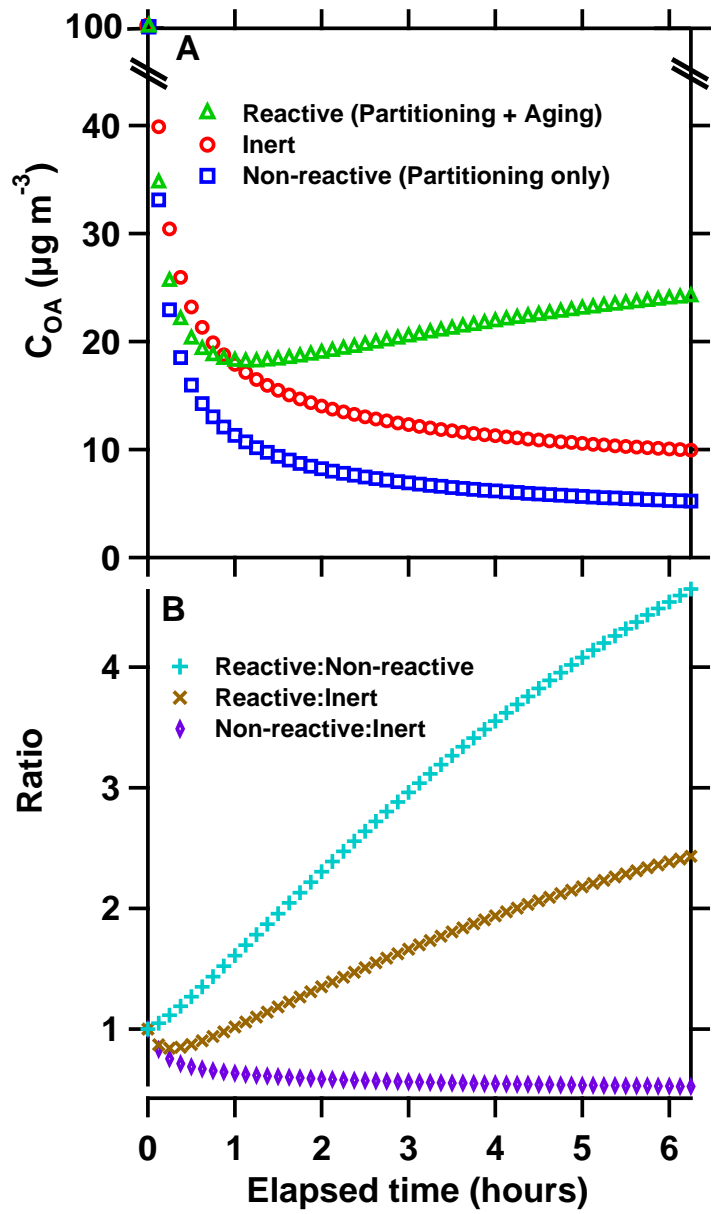

Fig. 8. Model predictions of the evolving OA concentrations in a biomass-burning plume. Panel (A) shows predicted concentrations for three cases: inert (non-volatile and non-reactive), non-reactive (semi-volatile but non-reactive) and reactive (semi-volatile and reacts according to the basis-set aging model) OA emissions. Panel (B) shows concentration ratios of the reactive to non-reactive and inert cases.

Biomass-burning is a very heterogeneous source with many different fuel types burning under a wide range of conditions. These experiments investigated emissions from one type of biomass-burning: wood fires burning inside of a wood stove. Wood burning in a stove likely involves a more homogenous fuel source and different, potentially more efficient, burning mode than other types of biomass burning sources such as wildfires or prescribed burns. In order to investigate a wider range of emission scenarios, we specifically conducted experiments with different fuel types and different burning modes (smoldering and flaming).

Our emissions data generally fall within the range of literature data for biomass-burning. For example, $\mathrm{CO} / \mathrm{CO}_{2}$ molar emission ratios in our experiments range from 7 to $71 \%$ with a median of $15 \%$. versus a range between 2 and $20 \%$ reported by field studies (Koppmann et al., 2005). The OC-to-EC ratio of our emissions ranged from 1.1 to 13 which is comparable to the range of values reported by field studies, 1.7 to 17.3 (Reid et al., 2005). The average $\mathrm{NO}_{\mathrm{x}}$ emission ratio for our experiments was $4( \pm 1) \times 10^{-4} \mathrm{~kg} \mathrm{NO}\left(\mathrm{kg} \mathrm{CO}_{2}\right)^{-1}$, which is on the low end of field data (Andreae and Merlet, 2001). The campaign primary $\mathrm{OC}$ emission factor (assuming an OM:OC ratio of 2.1 (Turpin and Lim, 2001) was $0.7 \pm 1.0 \mathrm{~g} \mathrm{C}$ $\left(\mathrm{kgCO}_{2}\right)^{-1}$ (average \pm standard deviation) which is also somewhat lower than field data (Andreae and Merlet, 2001). However, OC emissions measurements are difficult to compare because of potential differences in gas-particle partitioning of semivolatile organic compounds (Lipsky and Robinson, 2006; Shrivastava et al., 2006) and the treatment of filter sampling artifacts (Subramanian et al., 2004). Our ratios of benzene and toluene with $\mathrm{CO}$ were quite variable, but are in reasonable agreement with values from literature (de Gouw et al., 2006). The acetonitrile-to-CO ratios measured were a factor of 2 to 10 lower than most literature values. The fresh particle size distributions measured here are similar to published data for fire place emissions (Kleeman et al., 1999) but somewhat smaller than field measurements of fresh biomassburning plumes (Reid et al., 2005). This difference may be due to emissions in our experiments being more rapidly diluted than those in real plumes. While differences in particle size distribution will affect particle microphysical processes such as coagulation and condensation, this should not affect the equilibrium partitioning of SVOCs that is the critical process in aerosol aging.

Another important difference between our experiments and aging of real biomass-burning plumes is dilution. In real plumes the emissions are continuously diluted as they are advected downwind from the source. In contrast, the dilution ratio during the aging phase of our experiments was fixed. Therefore, the OA levels in a real plume depend on the relative importance of dilution-driven evaporation versus photochemical production.

The basis-set model was modified to investigate the competing effects of dilution and aging in plumes. The modified model used the parameterization of Trentmann et al. (2005) to dilute the emissions. This parameterization is based on measured $\mathrm{CO}$ dilution downwind of large scale savannah fires. The emissions were simultaneously aged using the "Modified" aging parameters listed in Table 3 and assuming a constant $\mathrm{OH}$ concentration of $4 \times 10^{6}$ molecules $\mathrm{cm}^{-3}$ to match conditions in our chamber experiments; this is somewhat lower than the average in-plume $\mathrm{OH}$ concentration of 7.7-17 $\times 10^{6}$ molecules $\mathrm{cm}^{-3}$ calculated by Trentmann et al. (2005). The initial POA concentration was $100 \mu \mathrm{g} \mathrm{m}^{-3}$, which is similar to aircraft data measured close to wildfires (Hobbs et al., 2003). The gas-particle partitioning of the fresh POA emissions was determined using the "Diesel" volatility distribution (Table 3 ).

Figure 8a presents model predictions for three different scenarios: inert POA (non-volatile and non-reactive), semivolatile OA that partitions but does not age, and 
semivolatile OA that partitions and ages via the mechanism discussed above. The decrease in concentration for the inert POA is due to dilution; Fig. 8a indicates that the model dilutes the emissions with clean air by about a factor of 10 over the six hour simulation period. The concentration of tracer species such as $\mathrm{CO}$ or $\mathrm{BC}$ follows the same profile as the inert POA. The OA concentration in the non-reactive (partitioning only) case falls more quickly than the inert species as dilution causes some of the semivolatile material to evaporate. Finally, the partitioning plus aging scenario shows that dilution-driven evaporation initially causes the OA concentration to decrease relative to the inert case, but within an hour of emission this decrease has been more than offset by photochemical production of new OA.

The magnitude of these changes can be better understood by comparing the time series of concentration ratios plotted in Fig. 8b. Concentration ratios with inert species such as $\mathrm{CO}$ are frequently used to correct for dilution in fire plume studies. Relative to an inert tracer, dilution-driven evaporation of the non-reactive semivolatile species reduces OA concentrations by about a factor of 2 . However, coupled dilution and aging causes the OA levels to increase by about a factor of 2 relative to an inert species. This increase is roughly equivalent to that observed in our chamber experiments without any dilution and similar to the OA enhancements observed in real fire plumes (Reid et al., 2005). Therefore, the model predicts dilution-driven evaporation of particle-phase SVOC is more than offset by the oxidation-driven formation of lessvolatile material which then partitions into the particle-phase. In fact, dilution actually shifts the primary-secondary split more towards SOA because dilution causes some of the POA to evaporate and increases the concentrations of low volatility vapors which are then oxidized to form new OA.

Acknowledgements. This research was supported by the EPA STAR program through the National Center for Environmental Research (NCER) under grant R833748. This paper has not been subject to EPA's required peer and policy review, and therefore does not necessarily reflect the views of the Agency. No official endorsement should be inferred. The PTR-MS and AMS were acquired with support from the NSF (ATM-0420842). The authors gratefully acknowledge Jose-Luis Jimenez for comments on a draft manuscript and Manish Shrivastava and Jeffrey Pierce for assistance with model configuration.

Edited by: M. Ammann

\section{References}

Abel, S. J., Haywood, J. M., Highwood, E. J., Li, J., and Buseck, P. R.: Evolution of biomass burning aerosol properties from an agricultural fire in southern Africa, Geophys. Res. Lett., 30, 1783, doi:1710.1029/2003GL017342, 2003.

Aiken, A. C., DeCarlo, P. F., Kroll, J. H., Worsnop, D. R., Huffman, J. A., Docherty, K. S., Ulbrich, I. M., Mohr, C., Kimmel,
J. R., Sueper, D., Sun, Y., Zhang, Q., Trimborn, A., Northway, M., Ziemann, P. J., Canagaratna, M. R., Onasch, T. B., Alfarra, M. R., Prevot, A. S. H., Dommen, J., Duplissy, J., Metzger, A., Baltensperger, U., and Jimenez, J. L.: O/C and OM/OC Ratios of Primary, Secondary, and Ambient Organic Aerosols with HighResolution Time-of-Flight Aerosol Mass Spectrometry, Environ. Sci. Technol., 2, 4478-4485, 2008.

An, W. J., Pathak, R. K., Lee, B., and Pandis, S. N.: Aerosol volatility measurement using an improved thermodenuder: Application to secondary organic aerosol, J. Aerosol. Sci., 38, 305-314, 2007.

Andreae, M. O. and Merlet, P.: Emission of trace gases and aerosols from biomass burning, Global Biogeochem. Cy., 15, 955-966, 2001.

Andreae, M. O., Rosenfeld, D., Artaxo, P., Costa, A. A., Frank, G. P., Longo, K. M., and Silva-Dias, M. A. F.: Smoking rain clouds over the Amazon, Science, 303, 1337-1342, 2004.

Bond, T. C., Streets, D. G., Yarber, K. F., Nelson, S. M., Woo, J. H., and Klimont, Z.: A technology-based global inventory of black and organic carbon emissions from combustion, J. Geophys. Res.-Atmos., 109, D14203, doi:14210.11029/12003JD003697, 2004.

Canagaratna, M. R., Jayne, J. T., Jimenez, J. L., Allan, J. D., Alfarra, M. R., Zhang, Q., Onasch, T. B., Drewnick, F., Coe, H., Middlebrook, A., Delia, A., Williams, L. R., Trimborn, A. M., Northway, M. J., DeCarlo, P. F., Kolb, C. E., Davidovits, P., and Worsnop, D. R.: Chemical and microphysical characterization of ambient aerosols with the aerodyne aerosol mass spectrometer, Mass Spectrom. Rev., 26, 185-222, 2007.

Carter, W., Cocker, D., Fitz, D., Malkina, I., Bumiller, K., Sauer, C., Pisano, J., Bufalino, C., and Song, C.: A new environmental chamber for evaluation of gas-phase chemical mechanisms and secondary aerosol formation, Atmos. Environ., 39, 7768-7788, 2005.

Christian, T. J., Kleiss, B., Yokelson, R. J., Holzinger, R., Crutzen, P. J., Hao, W. M., Shirai, T., and Blake, D. R.: Comprehensive laboratory measurements of biomass-burning emissions: 2. First intercomparison of open-path FTIR, PTR-MS, and GC- MS/FID/ECD, J. Geophys. Res.-Atmos., 109, D02311, doi:02310.01029/02003JD003874, 2004.

Crosier, J., Jimenez, J. L., Allan, J. D., Bower, K. N., Williams, P. I., Alfarra, M. R., Canagaratna, M. R., Jayne, J. T., Worsnop, D. R., and Coe, H.: Technical Note: Description and use of the new Jump Mass Spectrum mode of operation for the Aerodyne Quadrupole Aerosol Mass Spectrometers (Q-AMS), Aerosol Sci. Tech., 41, 865-872, 2007.

de Gouw, J. A., Warneke, C., Stohl, A., Wollny, A. G., Brock, C. A., Cooper, O. R., Holloway, J. S., Trainer, M., Fehsenfeld, F. C., Atlas, E. L., Donnelly, S. G., Stroud, V., and Lueb, A.: Volatile organic compounds composition of merged and aged forest fire plumes from Alaska and western Canada, J. Geophys. Res.-Atmos., 111, D10303, doi:10310.11029/12005JD006175, 2006.

Donahue, N. M., Robinson, A. L., Stanier, C. O., and Pandis, S. N.: Coupled partitioning, dilution, and chemical aging of semivolatile organics, Environ. Sci. Technol., 40, 2635-2643, 2006.

Grieshop, A. P., Donahue, N. M., and Robinson, A. L.: Is the Gas-Particle Partitioning in alpha-Pinene Secondary Or- 
ganic Aerosol Reversible?, Geophys. Res. Lett., 34, L14810, doi:14810.11029/12007GL029987, 2007.

Grieshop, A. P., Donahue, N. M., and Robinson, A. L.: Laboratory investigation of photochemical oxidation of organic aerosol from wood fires - Part 2: Analysis of aerosol mass spectrometer data, Atmos. Chem. Phys. Discuss., 8, 17095-17130, 2008, http://www.atmos-chem-phys-discuss.net/8/17095/2008/.

Hildemann, L., Klinedinst, D., Klouda, G., Currie, L., and Cass, G.: Sources of Urban Contemporary Carbon Aerosol, Environ. Sci. Technol., 28, 1565-1576, 1994.

Hobbs, P. V., Sinha, P., Yokelson, R. J., Christian, T. J., Blake, D. R., Gao, S., Kirchstetter, T. W., Novakov, T., and Pilewskie, P.: Evolution of gases and particles from a savanna fire in South Africa, J. Geophys. Res.-Atmos., 108, 8485, doi:8410.1029/2002JD002352, 2003.

Huffman, J. A., Mohr, C., Ulbrich, I. M., Cubison, M. J., Docherty, K. S., Onasch, T. B., Ziemann, P. J., and Jimenez, J. L.: Chemically-Resolved Volatility Measurements of Aerosol Sources, Environ. Sci. Technol., submitted, 2008.

Karl, T. G., Christian, T. J., Yokelson, R. J., Artaxo, P., Hao, W. M., and Guenther, A.: The Tropical Forest and Fire Emissions Experiment: method evaluation of volatile organic compound emissions measured by PTR-MS, FTIR, and GC from tropical biomass burning, Atmos. Chem. Phys., 7, 5883-5897, 2007, http://www.atmos-chem-phys.net/7/5883/2007/.

Kirchstetter, T. W. and Novakov, T.: Controlled generation of black carbon particles from a diffusion flame and applications in evaluating black carbon measurement methods, Atmos. Environ., 41, 1874-1888, 2007.

Kirchstetter, T. W., Novakov, T., and Hobbs, P. V.: Evidence that the spectral dependence of light absorption by aerosols is affected by organic carbon, J. Geophys. Res.-Atmos., 109, D21208, doi:21210.21029/22004JD004999, 2004.

Kleeman, M. J., Schauer, J. J., and Cass, G. R.: Size and composition distribution of fine particulate matter emitted from wood burning, meat charbroiling, and cigarettes, Environ. Sci. Technol., 33, 3516-3523, 1999.

Koo, B. Y., Ansari, A. S., and Pandis, S. N.: Integrated approaches to modeling the organic and inorganic atmospheric aerosol components, Atmos. Environ., 37, 4757-4768, 2003.

Koppmann, R., von Czapiewski, K., and Reid, J. S.: A review of biomass burning emissions - Part I: gaseous emissions of carbon monoxide, methane, volatile organic compounds, and nitrogen containing compounds, Atmos. Chem. Phys. Discuss., 5, 1045510516, 2005,

http://www.atmos-chem-phys-discuss.net/5/10455/2005/.

Lee, S., Kim, H. K., Yan, B., Cobb, C. E., Hennigan, C., Nichols, S., Chamber, M., Edgerton, E. S., Jansen, J. J., Hu, Y. T., Zheng, M., Weber, R. J., and Russell, A. G.: Diagnosis of aged prescribed burning plumes impacting an urban area, Environ. Sci. Technol., 42, 1438-1444, 2008.

Lelieveld, J., Crutzen, P. J., Ramanathan, V., Andreae, M. O., Brenninkmeijer, C. A. M., Campos, T., Cass, G. R., Dickerson, R. R., Fischer, H., de Gouw, J. A., Hansel, A., Jefferson, A., Kley, D., de Laat, A. T. J., Lal, S., Lawrence, M. G., Lobert, J. M., MayolBracero, O. L., Mitra, A. P., Novakov, T., Oltmans, S. J., Prather, K. A., Reiner, T., Rodhe, H., Scheeren, H. A., Sikka, D., and Williams, J.: The Indian Ocean Experiment: Widespread air pollution from South and Southeast Asia, Science, 291, 1031-1036,
2001.

Lim, Y. B. and Ziemann, P. J.: Products and mechanism of secondary organic aerosol formation from reactions of n-alkanes with $\mathrm{OH}$ radicals in the presence of $\mathrm{NO}_{\mathrm{x}}$, Environ. Sci. Technol. 39, 9229-9236, 2005.

Lipsky, E. M. and Robinson, A. L.: Effects of dilution on fine particle mass and partitioning of semivolatile organics in diesel exhaust and wood smoke, Environ. Sci. Technol., 40, 155-162, 2006.

Millet, D. B., Donahue, N. M., Pandis, S. N., Polidori, A., Stanier, C. O., Turpin, B. J., and Goldstein, A. H.: Atmospheric volatile organic compound measurements during the Pittsburgh Air Quality Study: Results, interpretation, and quantification of primary and secondary contributions, J. Geophys. Res.-Atmos., 110, D07S07, doi:10.1029/2004JD004601, 2005.

Ng, N. L., Kroll, J. H., Chan, A. W. H., Chhabra, P. S., Flagan, R. C., and Seinfeld, J. H.: Secondary organic aerosol formation from m-xylene, toluene, and benzene, Atmos. Chem. Phys., 7, 3909-3922, 2007, http://www.atmos-chem-phys.net/7/3909/2007/.

Nopmongcol, U., Khamwichit, W., Fraser, M. P., and Allen, D. T.: Estimates of heterogeneous formation of secondary organic aerosol during a wood smoke episode in Houston, Texas, Atmos. Environ., 41, 3057-3070, 2007.

Pankow, J. F.: An Absorption-Model of Gas-Particle Partitioning of Organic-Compounds in the Atmosphere, Atmos. Environ., 28, 185-188, 1994.

Pankow, J. F. and Asher, W. E.: SIMPOL.1: a simple group contribution method for predicting vapor pressures and enthalpies of vaporization of multifunctional organic compounds, Atmos. Chem. Phys., 8, 2773-2796, 2008, http://www.atmos-chem-phys.net/8/2773/2008/.

Peltier, R. E., Sullivan, A. P., Weber, R. J., Brock, C. A., Wollny, A. G., Holloway, J. S., de Gouw, J. A., and Warneke, C.: Fine aerosol bulk composition measured on WP-3D research aircraft in vicinity of the Northeastern United States - results from NEAQS, Atmos. Chem. Phys., 7, 3231-3247, 2007, http://www.atmos-chem-phys.net/7/3231/2007/.

Pierce, J. R., Engelhart, G. J., Weitkamp, E. A., Pathak, R. K., Pandis, S. N., Donahue, N. M., Robinson, A. R., and Adams, P. J.: Constraining particle evolution from wall losses, coagulation, and condensation-evaporation in smog-chamber experiments: optimal estimation based on size distribution measurements, Aerosol Sci. Tech., 42, 1001-1015, 2008.

Presto, A. A., Huff Hartz, K. E., and Donahue, N. M.: Secondary organic aerosol production from terpene ozonolysis, 1. Effect of UV radiation, Environ. Sci. Technol., 39, 7036-7045, 2005a.

Presto, A. A., Huff Hartz, K. E., and Donahue, N. M.: Secondary organic aerosol production from terpene ozonolysis, 2. Effect of $\mathrm{NO}_{\mathrm{x}}$ concentration, Environ. Sci. Technol., 39, 7046-7054, 2005b.

Ramanathan, V., Li, F., Ramana, M. V., Praveen, P. S., Kim, D., Corrigan, C. E., Nguyen, H., Stone, E. A., Schauer, J. J., Carmichael, G. R., Adhikary, B., and Yoon, S. C.: Atmospheric brown clouds: Hemispherical and regional variations in long-range transport, absorption, and radiative forcing, J. Geophys. Res.-Atmos., 112, D22S21, doi:10.1029/2006JD008124, 2007.

Reid, J., Hobbs, P., Ferek, R., Blake, D., Martins, J., Dunlap, M., and Liousse, C.: Physical, chemical, and optical properties of 
regional hazes dominated by smoke in Brazil, J. Geophys. Res., 103, 32059-32080, 1998.

Reid, J. S., Koppmann, R., Eck, T. F., and Eleuterio, D. P.: A review of biomass burning emissions - Part II: Intensive physical properties of biomass burning particles, Atmos. Chem. Phys., 5, 799-825, 2005,

http://www.atmos-chem-phys.net/5/799/2005/.

Robinson, A. L., Donahue, N. M., Shrivastava, M. K., Weitkamp, E. A., Sage, A. M., Grieshop, A. P., Lane, T. E., Pierce, J. R., and Pandis, S. N.: Rethinking Organic Aerosols: Semivolatile Emissions and Photochemical Aging, Science, 315, 1259-1262, 2007.

Robinson, A. L., Subramanian, R., Donahue, N. M., BernardoBricker, A., and Rogge, W. F.: Source apportionment of molecular markers and organic aerosol, 2. Biomass smoke, Environ. Sci. Technol., 40, 7811-7819, 2006.

Sage, A. M., Weitkamp, E. A., Robinson, A. L., and Donahue, N. M.: Evolving mass spectra of the oxidized component of organic aerosol: results from aerosol mass spectrometer analyses of aged diesel emissions, Atmos. Chem. Phys., 8, 1139-1152, 2008, http://www.atmos-chem-phys.net/8/1139/2008/.

Schauer, J. J. and Cass, G. R.: Source apportionment of wintertime gas-phase and particle-phase air pollutants using organic compounds as tracers, Environ. Sci. Technol., 34, 1821-1832, 2000.

Schauer, J. J., Kleeman, M. J., Cass, G. R., and Simoneit, B. R. T.: Measurement of emissions from air pollution sources, 3. C1-C-29 organic compounds from fireplace combustion of wood, Environ. Sci. Technol., 35, 1716-1728, 2001.

Seinfeld, J. H. and Pandis, S. N.: Atmospheric Chemistry and Physics - From Air Pollution to Climate Change, John Wiley \& Sons, New York, USA, 1998.

Shrivastava, M. K., Lane, T. E., Donahue, N. M., Pandis, S. N., and Robinson, A. L.: Effects of Gas-Particle Partitioning and Aging of Primary Emissions on Urban and Regional Organic Aerosol Concentrations, J. Geophys. Res.-Atmos., 113, D18301, doi:18310.11029/12007JD009735, 2008.

Shrivastava, M. K., Lipsky, E. M., Stanier, C. O., and Robinson, A. L.: Modeling semivolatile organic aerosol mass emissions from combustion systems, Environ. Sci. Technol., 40, 26712677, 2006.

Stanier, C. O., Pathak, R. K., and Pandis, S.: Measurements of the Volatility of Aerosols from alpha-Pinene Ozonolysis, Environ. Sci. Technol., 41, 2756-2763, 2007.
Strader, R., Lurmann, F., and Pandis, S. N.: Evaluation of secondary organic aerosol formation in winter, Atmos. Environ., 33, 48494863, 1999.

Subramanian, R., Khlystov, A. Y., Cabada, J. C., and Robinson, A. L.: Positive and negative artifacts in particulate organic carbon measurements with denuded and undenuded sampler configurations, Aerosol Sci. Tech., 38, 27-48, 2004.

Szidat, S., Jenk, T. M., Synal, H. A., Kalberer, M., Wacker, L., Hajdas, I., Kasper-Giebl, A., and Baltensperger, U.: Contributions of fossil fuel, biomass-burning, and biogenic emissions to carbonaceous aerosols in Zurich as traced by C-14, J. Geophys. Res.Atmos., 111, D07206, doi:07210.01029/02005JD006590, 2006.

Tanner, R., Parkhurst, W., and McNichol, A.: Fossil Sources of Ambient Aerosol Carbon Based on 14C Measurements, Aerosol Sci. Tech., 38, 133-139, 2004.

Trentmann, J., Andreae, M. O., and Graf, H. F.: Chemical processes in a young biomass-burning plume, J. Geophys. Res.-Atmos., 108, 4705, doi:4710.1029/2003JD003732, 2003.

Trentmann, J., Yokelson, R. J., Hobbs, P. V., Winterrath, T., Christian, T. J., Andreae, M. O., and Mason, S. A.: An analysis of the chemical processes in the smoke plume from a savanna fire, J. Geophys. Res.-Atmos., 110, D12301, doi:12310.11029/12004JD005628, 2005.

Turpin, B. J. and Lim, H. J.: Species contributions to PM $_{2.5}$ mass concentrations: Revisiting common assumptions for estimating organic mass, Aerosol Sci. Tech., 35, 602-610, 2001.

Turpin, B. J., Saxena, P., and Andrews, E.: Measuring and simulating particulate organics in the atmosphere: problems and prospects, Atmos. Environ., 34, 2983-3013, 2000.

Watson, J. G.: Visibility: Science and regulation, J. Air Waste Manage., 52, 628-713, 2002.

Weitkamp, E. A., Sage, A. M., Pierce, J. R., Donahue, N. M., and Robinson, A. L.: Organic aerosol formation from photochemical oxidation of diesel exhaust in a smog chamber, Environ. Sci. Technol., 41, 6969-6975, 2007.

Wotawa, G. and Trainer, M.: The influence of Canadian forest fires on pollutant concentrations in the United States, Science, 288, 324-328, 2000.

Zheng, M., Ke, L., Edgerton, E., Schauer, J., Dong, M., and Russell, A.: Spatial distribution of carbonaceous aerosol in the southeastern United States using molecular markers and carbon isotope data, J. Geophys. Res, 111, D10S06, doi:10.1029/2005JD006777, 2006. 